\title{
Nutrition in cryptogenic cirrhosis and chronic aggressive hepatitis
}

\author{
A. G. MORGAN, J. KELlEHER, B. E. WALKER, AND M. S. LOSOWSKY \\ From the Airedale General Hospital, Eastburn, Nr. Keighley, and the University Department of Medicine, \\ St. James's Hospital, Leeds
}

SUMMARY The nutritional status of 80 patients with non-alcoholic chronic liver disease was assessed by determination of various nutritional parameters in body fluids. With the exception of vitamin $C$ there was a higher incidence $(40 \%)$ of fat soluble vitamin deficiency (vitamins $A, E$, and carotene) than of the water soluble vitamins. Less than $10 \%$ of patients showed evidence of vitamin $B_{12}$, nicotinic acid, thiamin, or riboflavin deficiency, and $17 \%$ had evidence of folic acid deficiency. The presence of deficiency was not related to age of the patient or fat absorption, and an inadequate dietary intake was not a major cause of deficiency. The incidence of nutritional deficiency is less frequent in non-alcoholic as compared with alcoholic liver disease.

Malnutrition in chronic liver disease may have many causes including diminished food intake (Leevy et al., 1965; Leevy et al., 1970a, b; Linscheer, 1970) impaired intestinal absorption (Losowsky and Walker, 1969), and abnormal metabolism (Leevy et al., 1970a) and storage (Baker et al., 1964). While this is well documented in the American literature, it refers mainly to alcoholic liver disease which, in contrast with the British Isles (Stone et al., 1968), accounts for almost all the chronic liver disease seen in the United States of America (Powell and Klatskin, 1968).

In alcoholic liver disease, there are the additional factors of gastritis and anorexia produced by excess alcohol, diminished vitamin and protein intake due to social factors, maldigestion due to alcoholinduced pancreatic disease (van Goidsenhoven et al., 1963; Sun et al., 1967; Marin et al., 1969), and malabsorption due to alcohol (Halsted et al., 1973). Thus, it cannot be assumed that the nutritional status of patients with liver disease in this country is similar to that of the United States of America.

We know of no detailed nutritional information for chronic liver disease of the non-alcoholic variety and therefore we have carried out a broadly-based nutritional survey in patients with non-alcoholic cirrhosis and chronic aggressive hepatitis.

\section{Methods}

SUBJECTS

A total of 80 patients with non-alcoholic liver disease Received for publication 20 October 1975 were studied. Sixty had cryptogenic cirrhosis (26 men and 34 women). Patients below the age of 40 years were screened for Wilson's disease, and all patients had a liver biopsy which was stained for iron to exclude haemochromatosis. Tests for Australia antigen were negative in all. Twenty patients had liver biopsy findings of chronic aggressive hepatitis (three men and 17 women). The ages and relevant liver function tests for these patients are shown in Table 1.

The extent of alcohol ingestion was obtained from the history, discussion with members of the family, and medical observation. The patients who were included fell within the definitions of mild or moderate drinkers as used by Soterakis et al. (1973). No patient was included who either ingested alcohol daily or suffered from acute alcoholic intoxication. No patient showed liver biopsy features of alcoholic liver disease.

The nutritional parameters in the patients with liver disease were compared with those in $\mathbf{5 0}$ normal volunteer control subjects. These were fit, asymptomatic, friends or colleagues, with no past history of liver disease. Clinical examination was not performed but routine liver function tests were all within normal limits.

\section{PROCEDURES}

Plasma vitamin A was measured spectrofluorimetrically (Kahan, 1966), plasma carotene spectrophotometrically at $520 \mathrm{~m} \mu$ on a petroleum ether extract (Varley, 1962), and plasma vitamin E spectrofluorimetrically (Hanson and Warwick, 1966). Faecal fat 


\begin{tabular}{|c|c|c|c|c|c|c|c|}
\hline \multicolumn{2}{|l|}{ Age } & \multicolumn{2}{|c|}{ Bilirubin } & \multicolumn{2}{|c|}{$A L A T$} & \multicolumn{2}{|c|}{ Albumin } \\
\hline No. & Years & No. & $\mu M / l$ & No. & $I U / l$ & No. & $g / l$ \\
\hline $\begin{array}{r}7 \\
13 \\
29 \\
30 \\
1\end{array}$ & $\begin{array}{l}\text { Under } 30 \\
30-44 \\
45-59 \\
60-74 \\
75+\end{array}$ & $\begin{array}{r}30 \\
24 \\
15 \\
6 \\
6\end{array}$ & $\begin{array}{r}0-17 \cdot 0 \\
17 \cdot 1-34 \cdot 2 \\
34 \cdot 3-68 \cdot 4 \\
68 \cdot 5-102 \cdot 6 \\
102 \cdot 7-171 \cdot 0\end{array}$ & $\begin{array}{r}34 \\
10 \\
10 \\
1 \\
2\end{array}$ & $\begin{array}{r}0-50 \\
51-100 \\
101-200 \\
201-500 \\
500+\end{array}$ & $\begin{array}{r}4 \\
16 \\
40 \\
20\end{array}$ & $\begin{array}{l}10-20 \\
21-30 \\
31-40 \\
41-50\end{array}$ \\
\hline
\end{tabular}

Table 1 Distribution of age, bilirubin, ALAT (alanine amino-transferase, EC 2612 ) and albumin in 80 patients with chronic non-alcoholic liver disease

was measured on two to seven day inpatient faecal collections on a constant fat diet, by the method of van de Kamer et al. (1949), using polyethylene glycol as a continuous marker after at least a five day equilibration period. Leucocyte vitamin $C$ was measured by the method of Denson and Bowers (1961), whole blood riboflavin as described by Burch et al. (1948), urinary N-methyl nicotinamide by the method of Pelletier and Campbell (1962), on two successive 24 hour urine collections, transketolase (and thiamine pyrophosphate stimulation TPP) by the method of Schouten et al. (1964). Serum folate (Waters and Mollin, 1961), red cell folate (Hoffbrand et al., 1966), and serum vitamin $B_{12}$ (Anderson, 1964), concentration were measured by microbiological assay, using Lactobacillus casei (Hoff brand et al., 1966) and Euglena gracilis (Anderson, 1964) respectively. Serum iron and total iron binding capacity (TIBC) were determined on an autoanalyser by a modification of the method of Giovanniello et al. (1968). All samples for vitamin assays were collected after an overnight fast; heparin was used as an anticoagulant for determinations on plasma. All samples were stored frozen unless assayed on the same day of collection.

\section{Results}

The following levels were calculated as nutritionally abnormal (more than two standard deviations from control mean) for the various nutritional parameters. Vitamin A less than $1.53 \mu \mathrm{M} / 1$, carotene less than $0.85 \mu \mathrm{M} / 1$, vitamin $\mathrm{E}$ less than $145 \mu \mathrm{M} / 1$, vitamin $\mathrm{C}$ less than $0.83 \mathrm{fM} / \mathrm{WBC}$, riboflavin less than 170 $\mu \mathrm{M} / \mathrm{l}, \mathrm{N}$-methyl-nicotinamide less than $146 \mu \mathrm{M} / 24 \mathrm{~h}$, transketolase less than 29 IU/1, TPP stimulation greater than $56 \%$, serum folic acid less than $2 \cdot 2$ $\mu \mathrm{g} / \mathrm{l}$, red blood cell folate less than $110 \mu \mathrm{g} / \mathrm{l}$, vitamin $B_{12}$ less than $118 \mathrm{ng} / \mathrm{l}$, iron less than $10 \mu \mathrm{M} / \mathrm{l}$, and total iron binding capacity $50 \cdot 6-80 \mu \mathrm{M} / 1$.

The measurements were grouped as fat soluble vitamins (E, A, and carotene), water soluble vitamins (vitamin $\mathrm{C}$, riboflavin, nocotinic acid, and thiamin) and haematinics (folic acid, vitamin $B_{12}$, iron, and iron binding capacity). There was no signi- ficant difference for any measurements between those with chronic aggressive hepatitis and cirrhosis, and thus they have been combined.

\section{DIETARY INTAKE}

In 39 patients a detailed dietary history for the week before admission to hospital, was taken by a dietitian (Fig. 1).

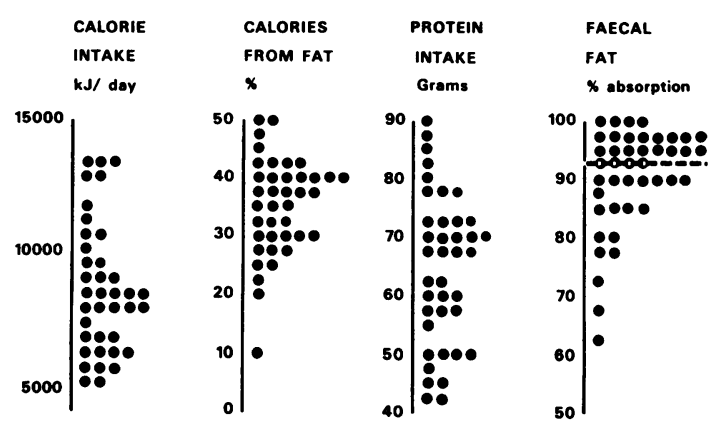

Fig. 1 Calorie intake, protein intake, the percentage calories from fat and faecal fat in patients with chronic liver disease. The dotted line represents the lower limit of normal for fat absorption.

Seventeen patients had a calorie intake more than $10 \%$ below that recommended by the Department of Health and Social Security (1969) (Recommended Intakes of Nutrients for the United Kingdom). Of these, 11 had calorie intakes more than $20 \%$; five more than $30 \%$; and one more than $40 \%$ below the recommended values. These recommended values assume average weight, but seven of the patients were very much underweight (average $13 \mathrm{~kg}$, range 9-25 $\mathrm{kg}$ below ideal weight).

The protein intake in four out of the 15 men, and six out of the 24 women was slightly below the recommended intake, but all were well above the minimum of $0.85 \mathrm{~g}$ protein $/ \mathrm{kg}$ body weight recommended by Davidson and Passmore (1966).

In 14 out of the 39 patients, fat accounted for less than the desirable minimum of $35 \%$ of the total calorie intake. 
FAECAL FAT

Faecal fat was measured in $\mathbf{4 3}$ patients. Steatorrhoea (absorption less than $93 \%$ dietary intake) was found in 19; eight absorbed between $80-90 \%$, and a further six patients absorbed less than $80 \%$ (Fig. 1).

FAT SOLUbLE Vitamins (Fig. 2)

Plasma vitamin E levels were estimated in 60 patients and subnormal levels were demonstrated in 23 $(38 \%)$.

Plasma vitamin A levels were low in $42 \%$ of patients tested (19 out of 45) and plasma carotene levels were low in nine out of 34 patients $(26 \%)$. In the 34 patients for whom both carotene and vitamin A levels were available, there was no correlation between these two parameters.

\section{WATER SOLUble Vitamins (Fig. 2)}

Leucocyte vitamin $\mathrm{C}$ levels were low in $35 \%$ of the patients tested (18 out of 52). Leucocyte vitamin C levels were subnormal in $25 \%$ of the patients with steatorrhoea, compared with $19 \%$ in those with normal faecal fats.

Whole blood riboflavin levels were estimated in 25 patients and was abnormal in one only.
Transketolase and TPP effect was measured in 31 patients. The transketolase was low in one patient only and the TPP effect was abnormally high in this patient. In two further patients, the TPP effect was abnormally high but the transketolase levels were within normal limits.

Twenty-four hour urinary N-methyl nicotinamide levels were estimated in 30 patients and were abnormal in four $(13 \%)$, and in four patients very high levels were found (above $560 \mu \mathrm{M} / 24 \mathrm{~h}$ ).

\section{HAEMATINICS (Fig. 3)}

Serum folate was subnormal in $17 \%$ of the patients (13 out of 75), red cell folate in $24 \%$ (nine out of 38 ), but these did not always occur in the same patient. Serum vitamin $B_{12}$ was below $110 \mathrm{ng} / 1$ in three patients and above $1000 \mathrm{ng} / \mathrm{l}$ in six patients.

Serum iron was estimated in 73 patients and 17 had subnormal values, three were below $3.6 \mu \mathrm{M} / \mathrm{l}$. The percentage of saturation of transferrin was plotted against serum iron, and a close correlation was shown $(r=0.93, \mathrm{P}<0.001)$. If we accept as abnormal only those patients with low values for both parameters (less than $10 \mu \mathrm{M} / 1$ and less than $16 \%$ saturation) evidence of iron deficiency was found in 14 out of 64 patients studied.

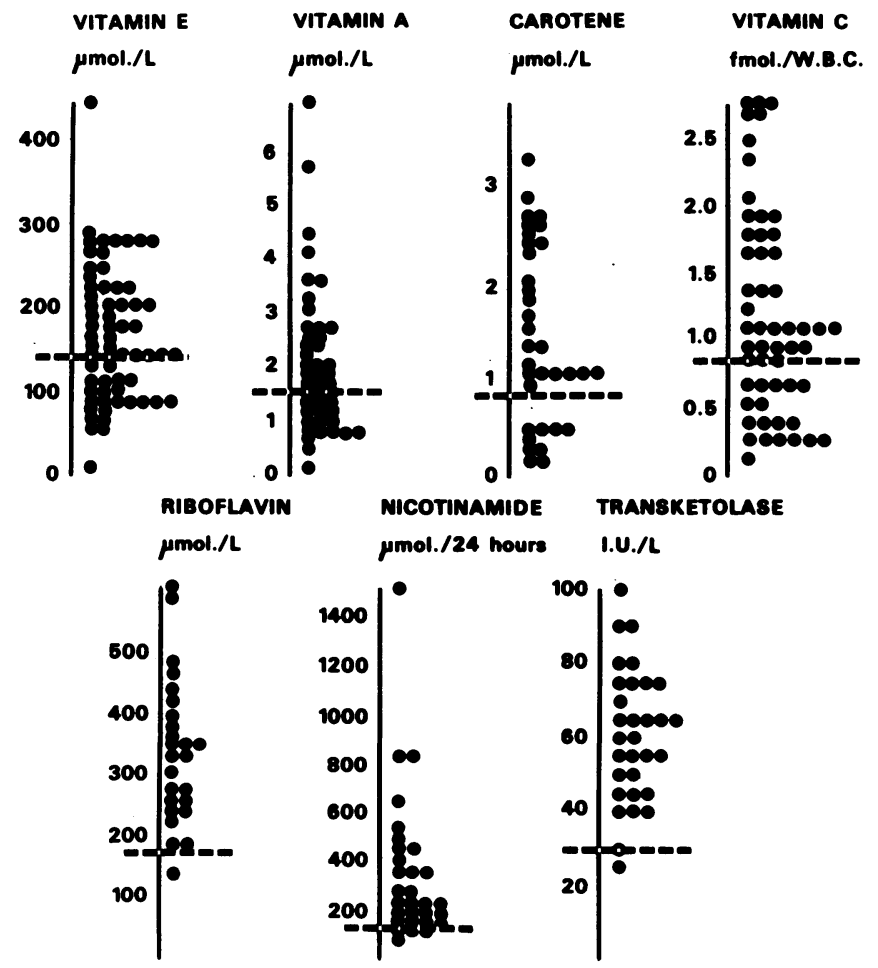

Fig. 2 Plasma levels of vitamins $E, A$, carotene and vitamin $C$, whole blood levels of riboflavin, and transketolase activity and urinary $N$-methyl nicotinamide excretion in patients with chronic liver disease. The dotted lines represent the lower limit of normal. 


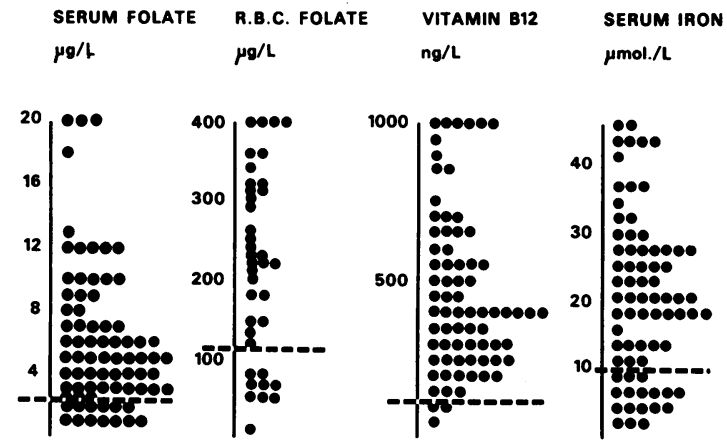

Fig. 3 Serum levels of folate, vitamin $B_{12}$ and iron, and red blood cell folate levels in patients with chronic liver disease. The dotted lines represent the lower limit of normal.

\section{Frequency of abnormal tests}

In Table 2 the results for the 58 patients who had five or more nutritional parameters measured, are summarized. The abnormal results are expressed as a percentage of the total tests performed on each patient. Sixteen per cent of these patients had no abnormal tests; $54 \%$ had between $10 \%$ and $30 \%$ abnormal.

Including results for all 80 patients, there was a higher incidence $(37 \%)$ of abnormal values for fat soluble vitamins than for water soluble vitamins $(17 \%)$ or haematinics $(17 \%)$.

The effect of age and steatorrhoea on both the fat and water soluble vitamins was determined and no significant correlation could be found.

\section{Discussion}

Single parameters of nutrition have been widely studied in patients with alcohol-induced liver disease and there is one broadly based nutritional survey (Leevy et al., 1965). In such patients, nutritional intake is frequently inadequate and unbalanced (Leevy et al., 1965; 1970b; Linscheer 1970; Leevy et al. 1970 a). Furthermore, alcohol, especially if combined with folate deficiency interferes with small bowel absorption (Halsted et al., 1973), may result in chronic pancreatitis (Sun et al., 1967), and can alter both vitamin storage and metabolism by its direct hepatotoxic effect (Leevy et al., 1965).
These factors are not applicable to most of the chronic liver disease seen in Great Britain.

Steatorrhoea is well documented in acute and chronic liver disease, whatever the aetiology (Sun et al., 1967; Marin et al., 1969; Losowsky and Walker, 1969; Williams and Sidorov, 1971), and even if anicteric (Summerskill and Moertel, 1962). Steatorrhoea, present in $44 \%$ of the 43 patients we studied, was never severe and seems unlikely to have been a major factor in the causation of nutritional deficiencies which were not infrequent in its absence.

Plasma levels of fat soluble vitamins were low in over a third of subjects. These subnormal levels were not related to age, or steatorrhoea. Subnormal plasma vitamin A levels are common in all liver disease (White et al., 1950; Ditlefsen and Støa, 1954) due to a defect in synthesis of the specific transport protein (Smith and Goodman, 1971). These low levels may nevertheless imply a defect in delivery of vitamin A to the tissues.

Blood thiamin levels, as measured by Leevy et al. (1965) provide an index of tissue thiamin stores, while the normal level for blood transketolase activity, present in almost all our patients, reflects both availability of thiamin and the ability of the liver to convert thiamin into its metabolically active form (Fennelly et al., 1967). In the one patient with a low transketolase activity, the addition in vitro of thiamine pyrophosphate produced an abnormally large effect, indicating either pre-existing thiamin deficiency, or a failure of its phosphorylation, a defect sometimes seen in alcoholic cirrhosis (Konttinen et al., 1970). The absence of evidence of thiamin deficiency in our patients contrasts strikingly with the data of Leevy et al. (1965) in patients with alcoholic liver disease and with the data of Konttinen et al. (1970) in chronic alcoholic subjects. The latter authors found low blood transketolase activities, and, in those patients with marked evidence of liver disease, this was not corrected by thiamine pyrophosphate, suggesting apoenzyme deficiency.

In man, nicotinic acid is mainly excreted as $\mathrm{N}$ methylnicotinamide (NMN) or the 6 pyridine derivative. A small proportion of our patients had very high urinary NMN levels, as reported in alcoholic cirrhosis by Gabuzda and Davidson (1962); the explanation for this is unknown. Leevy et al. (1965) found low blood nicotinic acid levels in almost a quarter of patients with alcoholic cirrhosis, while only $13 \%$ of our patients had low urinary NMN levels.

\begin{tabular}{llllllll}
\hline & \multicolumn{1}{l}{ \% of abnormal tests per patient } & & & & \\
\cline { 2 - 8 } & 0 & $0-9$ & $10-19$ & $20-29$ & $30-39$ & $40-49$ & $50-59$ \\
\hline$\%$ of patients & 16 & 5 & 25 & 29 & 14 & 3 & 5 \\
\hline
\end{tabular}

Table 2 Incidence of abnormal nutritional parameters in 58 patients who had more than five tests performed 
Leucocyte ascorbic acid estimations gave low results in $35 \%$ of our patients. This was not age related, although vitamin $C$ levels fall with age in normal subjects (Brook and Grimshaw, 1968). A higher proportion of our patients had evidence of ascorbic deficiency than those of Leevy et al. (1965) probably reflecting greater sensitivity of leucocyte ascorbic acid than serum levels as a test of deficiency. Iron deficiency may mask ascorbic acid deficiency (Jacobs et al., 1971) and leucocyte vitamin $C$ was subnormal in $40 \%$ of our patients (16 out of 40 ) with a normal serum iron, but only in $10 \%$ (one out of 10 ) in those with low serum iron.

Low red cell folate occurred in $24 \%$ and low serum folate in $17 \%$ of our patients but not always together (Williams and Girdwood, 1970) and in none was there megaloblastic change or anaemia. Severe folic acid deficiency with associated megaloblastic change is common in alcoholic liver disease (Herbert et al., 1963; Klipstein and Lindenbaum, 1965; Leevy et al., 1965; Eichner and Hillman 1971); dietary deficiency appears to be the major cause (Klipstein and Lindenbaum, 1965; Eichner and Hillman, 1971) but contributory factors may be impaired absorption (Halsted et al., 1971), increased requirements due to gastrointestinal bleeding, hypersplenism, or haemolysis (Klipstein and Lindenbaum, 1965), and decreased hepatic storage (Cherrick et al., 1965).

Serum $B_{12}$ was low in three patients only and these three had a megaloblastic marrow. In six patients the $B_{12}$ level was above $1000 \mathrm{ng} / \mathrm{l}$, perhaps mirroring the presence of hepatocellular damage and subsequent $B_{12}$ release (Joske, 1963). Five of these six patients were jaundiced and three out of four had a raised serum ALAT.

It appears that serum iron and percentage saturation of transferrin can be used to indicate iron status in patients with liver disease, since we found they were closely correlated despite the complicating factors of increased circulating ferritin (Lipschitz et $a l ., 1974)$ and changes in transferrin concentration consequent upon the liver disease. Evidence of iron deficiency was found in almost a quarter of the patients. Iron stores of alcohol abusers and patients with cirrhosis are usually diminished or normal (Kimber et al., 1964; Lundvall et al., 1969) but a small proportion of patients with cirrhosis have increased iron stores (Kimber et al., 1964).

Fat soluble vitamin deficiency was commoner than deficiency of water soluble vitamins. This may reflect malabsorption of fat soluble vitamins due to bile salt deficiency in liver disease. Leevy et al. (1965) found that all of his patients with alcoholic cirrhosis had low circulating levels of at least two vitamins, while abnormalities in our patients were much less common probably because our patients reflect the nutritional effects of the liver disease without the added effects of alcoholism and its dietary and metabolic concomitants.

\section{References}

Anderson, B. B. (1964). Investigations into the Euglena method for the assay of the vitamin $B_{12}$ in serum. Journal of Clinical Pathology, 17, 14-26.

Baker, H., Frank, O., Ziffer, H., Goldfarb, S., Leevy, C. M. and Sobotka, H. (1964). Effect of hepatic disease on liver B-complex vitamin titers. American Journal of Clinical Nutrition, 14, 1-6.

Brook, M., and Grimshaw, J. J. (1968). Vitamin C concentration of plasma and leukocytes as related to smoking habit, age and sex of humans. American Journal of Clinical Nutrition, 21, 1254-1258.

Burch, H. B., Bessey, O. A., and Lowry, O. H. (1948.) Fluorimetric measurements of riboflavin and its natural derivatives in small quantities of blood serum and cells. Journal of Biological Chemistry, 175, 457-470.

Cherrick, G. R., Baker, H., Frank, O., and Leevy, C. M. (1965). Observations on hepatic avidity for folate in Laennec's cirrhosis. Journal of Laboratory and Clinical Medicine, 66, 446-451.

Davidson, S., and Passmore, R. (1969). Human Nutrition and Dietetics, 4th edn. Livingstone: Edinburgh.

Denson, K. W., and Bowers, E. F. (1961). The determination of ascorbic acid in white blood cells. A comparison of WBC ascorbic acid and phenolic acid excretion in elderly patients. Clinical Science, 21, 157-162.

Department of Health and Social Security (1969). Recommended Intakes of Nutrients for the United Kingdom. H.M.S.O.: London.

Ditlefsen, E-M. L., and Støa, K. F. (1954). Vitamin A and carotenoid levels in blood serum with special reference to values observed in diseases of the liver. Scandinavian Journal of Clinical and Laboratory Investigation, 6, 210-216.

Eichner, E. R., and Hillman, R. S. (1971). The evolution of anemia in alcoholic patients. American Journal of Medicine, 50, 218-232.

Fennelly, J., Frank, O., Baker, H., and Leevy, C. M. (1967). Red blood cell-transketolase activity in malnourished alcoholics with cirrhosis. American Journal of Clinical Nutrition, 20, 946-949.

Gabuzda, G. J., and Davidson, C. S. (1962). Tryptophan and nicotinic acid metabolism in patients with cirrhosis of the liver. American Journal of Clinical Nutrition, 11, 502-508.

Giovanniello, T. J., Di Benedetto, G., Palmer, D. W., and Peters, T. (1968). Fully and semi-automated methods for the determination of serum iron and total iron-binding capacity. Journal of Laboratory and Clinical Medicine, 71, 874-883.

Goidsenhoven van, G. E., Henke, W. J., Vacca, J. B., and Knight Jr W. A. (1963). Pancreatic function in cirrhosis of the liver. American Journal of Digestive Diseases, 8, 160173.

Halsted, C. H., Robles, E. A., and Mezey, E. (1971). Decreased jejunal uptake of labeled folic acid ( $\left.{ }^{3} \mathrm{H}-\mathrm{PGA}\right)$ in alcoholic patients: roles of alcohol and nutrition. New England Journal of Medicine, 285, 701-706.

Halsted, C. H., Robles, E. A., and Mezey, E. (1973). Intestinal malabsorption in folate-deficient alcoholics. Gastroenterology, 64, 526-532.

Hansen, L. G., and Warwick, W. J. (1966). A fluorimetric micro method for serum tocopherol. American Journal of Clinical Pathology, 46, 133-138.

Herbert, V., Zalusky, R., and Davidson, C. S. (1963). Corre- 
lation of folate deficiency with alcoholism and associated macrocytosis, anemia, and liver disease. Annals of Internal Medicine, 58, 977-988.

Hoffbrand, A. V., Newcombe, B. F. A., and Mollin, D. L. (1966). Method of assay of red cell folate activity and the value of the assay as a test for folate deficiency. Journal of Clinical Pathology, 19, 17-28.

Jacobs, A., Greenman, D., Owen, E., and Cavill, I. (1971). Ascorbic acid status in iron-deficiency anaemia. Journal of Clinical Pathology, 24, 694-697.

Joske, R. A. (1963). The vitamin $B_{12}$ content of human liver tissue obtained by aspiration biopsy. Gut, 4, 231-235.

Kahan, J. (1966). A method for the fluorimetric determination of vitamin A. Scandinavian Journal of Clinical and Laboratory Investigation, 18, 679-690.

Kamer, J. H., van de, Huinink, H. ten. B., and Weyers, H. A. (1949). Rapid method for the determination of fat in feces. Journal of Biological Chemistry, 177, 347-355.

Kimber, C., Deller, D. J., Ibbotson, R. N., and Lander, H. (1965). The mechanism of anaemia in chronic liver disease. Quarterly Journal of Medicine, 34, 33-64.

Klipstein, F. A., and Lindenbaum, J. (1965). Folate deficiency in chronic liver disease. Blood, 25, 443-456.

Konttinen, A., Louhija, A., and Härtel, G. (1970). Blood transketolase in assessment of thiamine deficiency in alcoholics. Annales Medicinae Experimentalis et Biologiae Fenniae, 48, 172-175.

Leevy, C. M., Baker, H., tenHove, W., Frank, O., and Cherrick, G. R. (1965). B-complex vitamins in liver disease of the alcoholic. American Journal of Clinical Nutrition, 16, 339-346.

Leevy, C. M., Tamburro, C., and Smith, F. (1970a). Alcoholism, drug addiction and nutrition. Medical Clinics of North America, 54, 1567-1575.

Leevy, C. M., Thompson, A., and Baker, H. (1970b). Vitamins and liver injury. American Journal of Clinical Nutrition, 23, 493-499.

Linscheer, W. G. (1970). Malabsorption in cirrhosis. American Journal of Clinical Nutrition, 23, 488-492.

Lipschitz, D. A., Cook, J. D., and Finch, C. A. (1974). A clinical evaluation of serum ferritin as an index of iron stores. New England Journal of Medicine, 290, 1213-1216.

L.osowsky, M. S., and Walker, B. E. (1969). Liver disease and malabsorption. Gastroenterology, 56, 589-600.

Lundvall, O., Weinfeld, A., and Lundin, P. (1969). Iron stores in alcohol abusers. I. Liver iron. Acta Medica Scandinavica, 185, 259-269.

Marin, G. A., Clark, M. L., and Senior, J. R. (1969). Studies of malabsorption occurring in patients with Laennec's cirrhosis. Gastroenterology, 56, 727-736.

Pelletier, O., and Campbell, J. A. (1962). A rapid method for the determination of $\mathrm{N}$-methylnicotinamide in urine. Analytical Biochemistry, 3, 60-67.

Powell, W. J. Jr, and Klatskin, G. (1968). Duration of survival in patients with Laennec's cirrhosis. American Journal of Medicine, 44, 406-420.

Schouten, H., Statius van Eps, L. W., and Boudier, A. M. S. (1964). Transketolase in blood. Clinica Chimica Acta, 10, 474-476.

Smith, F. R., and Goodman, D. S. (1971). The effects of diseases of the liver, thyroid, and kidneys on the transport of vitamin A in human plasma. Journal of Clinical Investigation, 50, 2426-2436.

Soterakis, J., Resnick, R. H., and Iber, F. I. (1973). Effect of alcohol abstinence on survival in cirrhotic portal hypertension. Lancet, 2, 65-67.

Stone, W. D., Islam, N. R. K., and Paton, A. (1968). The natural history of cirrhosis. Quarterly Journal of Medicine, 37, 119-132.

Summerskill, W. H. J., and Moertel, C. G. (1962). Malabsorption syndrome associated with anicteric liver disease. Gastroenterology, 42, 380-392.

Sun, D. C. H., Albacete, R. A., and Chen, J. K. (1967). Malabsorption studies in cirrhosis of the liver. Archives of Internal Medicine, 119, 567-572.

Varley, H. (1962). Practical Clinical Biochemistry, 3rd edn. Heinemann: London.

Waters, A. H., and Mollin, D. L. (1961). Studies on the folic acid activity of human serum. Journal of Clinical Pathology, 14, 335-344.

White, D. P., Bone, F. C., Ruffin, J. M., and Taylor, H. (1950). Further observations on the value of plasma vitamin A determinations in the differential diagnosis of jaundice. Gastroenterology, 14, 541-548.

Williams, I. R., and Girdwood, R. H. (1970). The folate status of alcoholics. Scottish Medical Journal, 15, 285-288.

Williams, C. N., and Sidorov, J. J. (1971). Steatorrhoea in patients with liver disease. Canadian Medical Association Journal, 105, 1143-1146. 